\title{
ANTERIOR DISLOCATION OF THE LENS IN MARFAN'S SYNDROME*
}

\author{
BY \\ D. P. CHOYCE \\ Southend General Hospital, Essex \\ Case Report
}

A girl aged 14, coming from a family several members of which suffer from Marfan's syndrome, has many of the usual components of the syndrome, including a high arched palate, arachnodactyly, and microphakia, with congenital dislocation of the lenses. The condition was recognized when she was about 8 years old, since when she has been wearing an aphakic correction (+10 D sph. right and left) which normally gives her a visual acuity of $6 / 6$ in both eyes.

On November 23, 1956, she bent down to pick something off the schoolroom floor, and when she got up found that the sight of the right eye was blurred. When she was seen later that day the right lens was dislocated forward into the anterior chamber, where it could be made to float freely about by altering her posture. She was conscious of a faint irritation of the eye, but no pain, the ocular tension being normal. The lens was perfectly clear and irregularly shaped, as shown by the Figure. The pupil behind it was miotic. The visual acuity in the right eye was reduced to counting fingers.

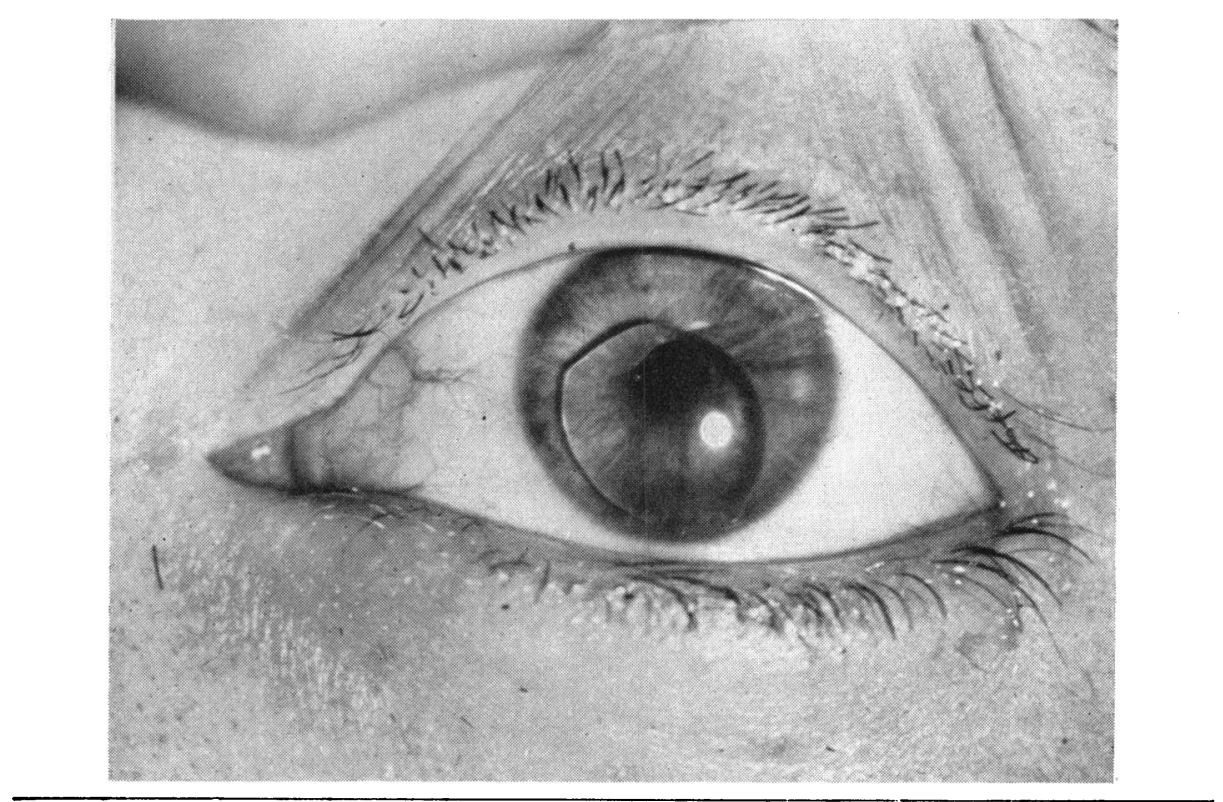

* Received for publication February 5, 1957.

$$
446
$$


Management of the Case.-Mindful of reports of cases in which the lenses can be transferred without much difficulty from anterior to posterior chamber, as described by Das Gupta and Basu (1955), it was decided to try to persuade the dislocated lens to return into the posterior chamber whence it came. The pupil was dilated with homatropine and, by positioning the patient on the operating table, the lens was manœuvred over the pupil, and pressure made on it through the overlying cornea. Unfortunately, instead of passing freely into the posterior chamber, it became gripped by the iris sphincter, with the upper pole behind the iris and the lower pole still in the anterior chamber. No amount of stimulation, either pharmacological or mechanical, could persuade the iris to release its hold.

Within 12 hours the patient was complaining of pain, and the eye was in a state of acute congestive glaucoma. The ocular tension had risen to $80-90 \mathrm{~mm}$. $\mathrm{Hg}$ (Schiötz), and the cornea was oedematous. $500 \mathrm{mg}$. of Diamox, followed by $250 \mathrm{mg}$. 6-hrly, succeeded in reducing the pressure to $50 / 55 \mathrm{~mm}$. $\mathrm{Hg}$ the next day, but the patient was still in pain and the cornea still oedematous. Operation was therefore indicated, albeit under conditions very much less propitious than if it had been undertaken when the lens was floating freely in the anterior chamber.

Anaesthesia.-In order to obtain maximum relaxation, the operation was performed under general anaesthesia.

First, an intravenous infusion was set up consisting of Pethidine, Phenergan, and Largactil. Anaesthesia was induced with intravenous thiopentone. Intubation was carried out under intravenous scoline, and anaesthesia was maintained with endotracheal nitrous oxide and oxygen, supplemented by a continuation of the above intravenous infusion. A further dose of thiopentone was given before surgery was begun.

Operation.-After the eye had been fixed with a superior rectus stitch, a small incision was made at the superior limbus with a von Graefe knife from 10 o'clock to 2 o'clock. In the middle of inserting the first cornea-scleral suture, the iris suddenly released the lens which shot out of the eye, and the section bulged ominously. In order to close the section securely, it was necessary to perform a wide complete iridectomy; fortunately, no vitreous was lost, though obviously its anterior surface was greatly disturbed.

Result.-The post-operative course was prolonged owing to considerable corneal oedema. However, good healing eventually took place, and 3 months after the operation the patient's vision is once again $6 / 6$ with her aphakic correction. She complains somewhat of the additional light let in by the superior iris coloboma.

The dimensions of the lens were $7.5 \times 6.5 \times 4 \mathrm{~mm}$., well illustrating the microphakia which is usually part of the syndrome.

\section{Discussion}

It cannot be assumed that, because a lens dislocates readily into the anterior chamber, it will prove equally easy to replace it in the posterior chamber. The rapidity with which acute congestive glaucoma developed once the lens became trapped by the iris was very striking. The danger to the eye is probably less if lens extraction is undertaken as soon as anterior dislocation occurs without attempting to replace the lens in the posterior chamber. Although, to date, aphakic detachment has not occurred in the operated eye, we feel that the danger of this happening has been made 
greater by the comparatively clumsy operative procedure to which the patient was subjected.

\section{Summary}

(1) A case of spontaneous anterior dislocation of the lens in Marfan's syndrome is described. An attempt to replace the lens in the posterior chamber led to the onset of acute congestive glaucoma.

(2) Our experience suggests that, when anterior dislocation occurs, the right procedure is to remove the lens without delay.

I am indebted to Dr. C. H. Pryor for describing the anaesthetic which he gave, and to Mr. J. Wood for the illustration.

\section{REFERENCE}

DAS GuPTA, B. K., and BASU, R. K. (1955). British Journal of Ophthalmology, 39, 566.

\section{BOOK REVIEW}

Neurology of the Ocular Muscles. By D. G. Cogan. 2nd edition, 1956. Pp. 296, 86 figs, Bibl. Blackwell, London. (63s.)

The second edition of "Neurology of the Ocular Muscles" has been enlarged to 296 pages and, apart from new work which has been added, particularly concerning the cerebellum, there have been some changes in emphasis. Thus, the myopathies as they affect the extra-ocular muscles are described in greater detail, and internuclear ophthalmoplegia receives more attention as important evidence of multiple sclerosis when bilateral, and of vascular disease when unilateral. Skew deviation and the difficulties of its interpretation are discussed.

The text has all the qualities of authority drawn from practical experience, although every page shows evidence of a deep knowledge of the literature. There are no less than 1,141 references, which take up 54 pages of the book, and a further 11 pages are given over to an excellent index. The subject matter is written in a gentle, pleasing style, beginning with the elements of gross anatomy which we all know so well, and gradually increasing in complexity as the author reaches the supranuclear connexions of the ocular motor system, and passes on to the real difficulties of nystagmus and its associated syndromes. It is a long time since the reviewer has gained so much pleasure in reading a text-book of medicine, and enjoyed throughout the lucidity of language and expression. The book can be highly recommended for senior students and for all practising ophthalmologists as a delight in store, and as a practical guide in difficult clinical problems. 